\title{
"Tabule e tabu": no palco uma salada de gênero, sexualidade, política e revolução a partir do cómico, se não fosse trágico*
}

TABULE Y TABU: ON STAGE A SALAD OF GENDER, SEXUALITY,

POLITICS AND REVOLUTION

TABULE Y TABU: EN EL ESCENARIO UNA ENSALADA DE GÉNERO, SEXUALIDAD, POLITICA Y REVOLUCIÓN

\section{José Maria Lopes Júnior **}

Cuadernos de Música, Artes Visuales y Artes Escénicas

/Volumen 13 - Número 1 / Enero - Junio de 2018

/ ISSN 1794-6670/ Bogotá, D.C., Colombia / pp. 103-115

Fecha de recepción: 14 de mayo de 2017

Fecha de aceptación: 6 de junio de 2017

Disponible en línea: 6 de diciembre de 2017

doi:10.11144/javeriana.mavae13-1.ttnp

** Professor Adjunto da Universidade Federal de Rondônia (desde 2008) atuando Curso de Licenciatura em Teatro do Departamento de Artes. Doutor em Artes Cências: Mito-drama: Processos de Ensino e Aprendizagem de Teatro com Indígenas de Rondônia e possui Mestrado em Letras/ Estudos Literários - Graduação em Letras/Licenciatura em Espanhol pela Universidade Federal de Minas Gerais. 


\section{Resumen}

Este artículo presenta los caminos y las reflexiones de la investigación y práctica escénica del espectáculo Tabule, una tragicomédia árabe. La obra fue presentada por primera vez en noviembre de 2011 en el Sesc Rondônia en medio de la Revolución árabe. El trabajo aborda el processo de escritura del texto dramático con énfasis en la elección de los temas y en los procesos de escenificación, privilegiando el montaje de un unipersonal. Usando el recurso de la comedia, pero "riendo para no llorar", la obra dialoga con el contexto histórico trayendo cuestiones de género, sexualidad, libertades, xenofobia, terrorismo y migraciones. Partiendo de la voz de una libanesa que en sus flujos migratorios vivió en la piel las revoluciones del mundo árabe. Zahara, ya en Brasil, lleva para el escenario un relato/testimonio sensible de lo que es y fue para ella ser mujer tanto en el mundo árabe como en Brasil.

Palabras claves: teatro; Oriente Medio; Primavera árabe cuestiones de género; 11-S

\section{Abstract}

This article presents the reflections of the research and scenic practice of the play Tabule, an Arab tragicomedy. The play was first performed in November 2011 at SESC Rondônia when the Arab Spring broke out. The work brings the writing process of the dramatic text with emphasis on the themes and the processes of staging, privileging the assembly of a unipersonal. Using the comic's resource, but "laughing not to cry", the work dialogues with the historical context regarding the west and east bringing to the issues of gender, sexuality, liberties, xenophobia, terrorism and migration. From the voice of a Lebanese woman who in her migratory flows witnessed and felt on the skin the revolutions of the Arab world. Zahara, already in Brazil, brings to the stage a sensitive account / testimony of what is / was for her to be a woman both in the Arab world and in Brazil.

Keywords: theater; Middle East; Arab Spring; gender issues; September 11th

\section{Resumo}

Este artigo apresenta os caminhos e reflexões da pesquisa e prática cênica do espetáculo Tabule, uma tragicomédia árabe. A peça foi apresentada pela primeira vez em novembro de 2011 no Sesc Rondônia quando eclodiu a Primavera Árabe. O trabalho traz o processo de escrita do texto dramático com ênfase na escolha dos temas e nos processos de encenação, privilegiando a montagem de um unipessoal. Usando o recurso do cómico, mas "rindo para não chorar", a obra dialoga com o contexto histórico no que tange o ocidente $x$ oriente trazendo às questões de gênero, sexualidade, liberdades, xenofobia, terrorismo e migrações. A partir da voz de uma libanesa que em seus fluxos migratórios presenciou e sentiu na pele as revoluções do mundo árabe. Zahara, já no Brasil, leva para o palco um relato/ depoimento sensível do que é/foi para ela ser mulher tanto no mundo árabe como no Brasil.

Palavras chave: teatro; Oriente Médio; Primavera Árabe; Questões de Gênero; 11 de setembro 


\section{INTRODUÇÃO}

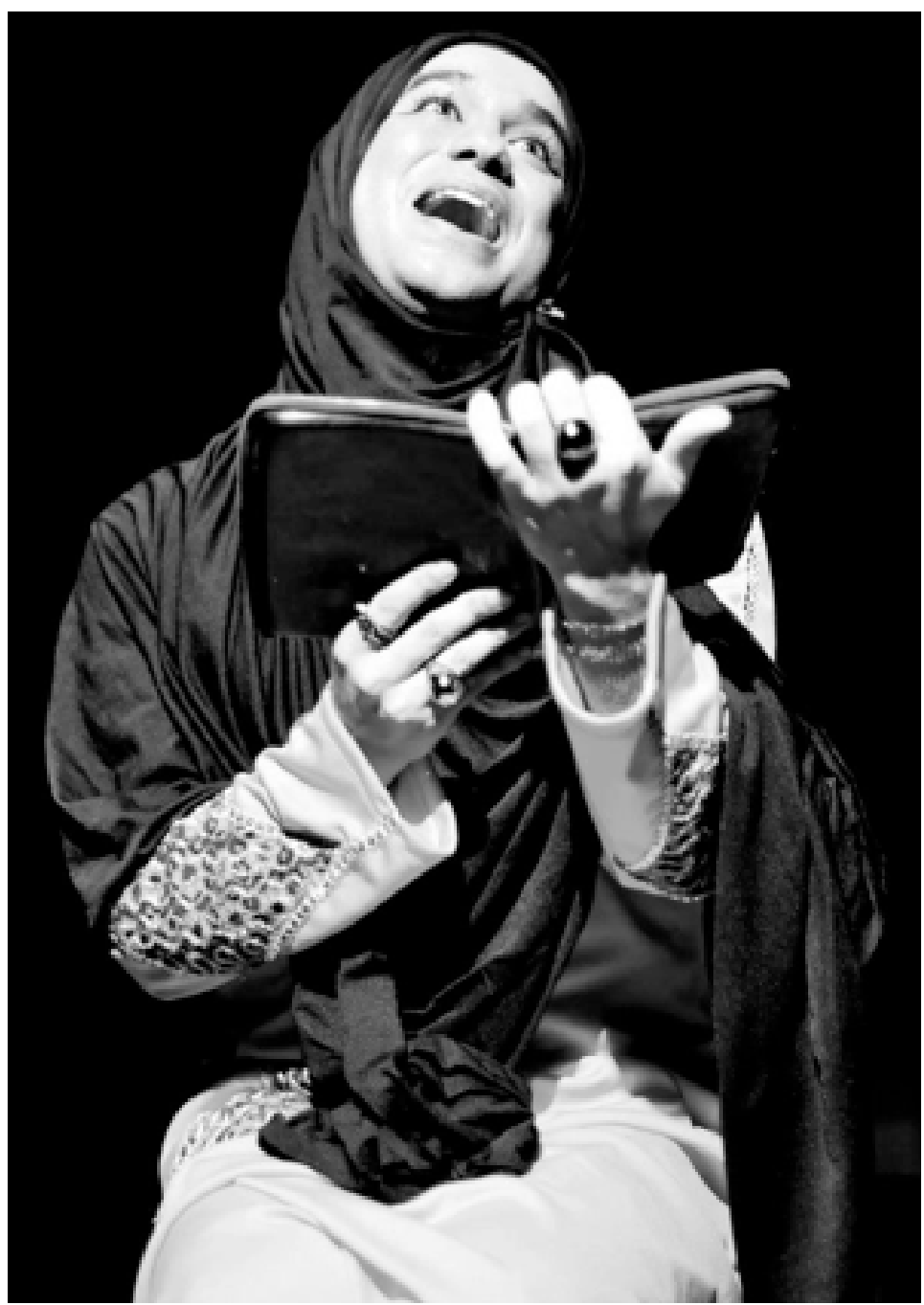

Foto: Avener Prado

Em janeiro de 2011 estava de férias em Nanuque, Minas Gerais, na casa de minha família. Minha mãe, Jurrene, filha de libanês, Cheab Mohamed Yahhia, estava fazendo esfirras de zatar com azeite, um ingrediente típico da culinária libanesa e muito presente na mesa da minha casa durante infância e adolescência e que até hoje continua presente na minha geladeira. A comida árabe, depois da brasileira, é a minha favorita e sempre negociei entre as duas. 
Esse fato (a comida árabe) poderia passar despercebido, mas, neste caso ele é um eixo norteador: desde pequeno, entre esfirras e tabule, escutava as histórias do meu avô, seus relatos sobre o Líbano, Beirute, Aramoun (sua terra natal, um povoado nas montanhas libanesas muito próximo a Beirute), sua chegada ao Brasil em 11 de maio de 1938, então com 28 anos de idade e há dez anos antes da criação do conflituoso Estado de Israel.

Assim, além da culinária árabe que sempre foi presente em minha casa - tabule, fatuche, homus, kibeh, babaghouge, esfirras, zátar, charutos e coalhada seca etc, - as constantes histórias contra judeus, ingleses, americanos etc. também estavam presentes. Tenho um tio, casado com minha tia Suaed, que se chama Israel. Entre a família, sempre se conta o episódio que quando o meu avô foi apresentado pelo suposto pretendente da minha tia, com o nome de Israel, este foi recebido com balas de revólver. Demorou muitos anos para que eu entendesse o ocorrido e qual a relação entre o nome do meu padrinho, Israel, e o fato do meu avô nunca ter aceitado esse casamento e ter recebido o rapaz com bala.

Outro ponto importante de se destacar tem relação com a minha avó. Meu avô teve "algumas várias mulheres" e com elas teve cinco filhos no total. Ele teve filhos com três mulheres diferentes. No entanto, todos os filhos ficaram com ele e ainda quando todos eram pequenos, a babá, Maria, brasileira e baiana de Vitória da Conquista, acabou criando todos e assumindo o lugar de mãe das crianças. Ela foi chamada pelos netos e netas de avó. Ou seja, a babá, que cuidava dos filhos do meu avô com outras mulheres, não teve filhos e acabou se tornando a companheira dele pelo resto de sua vida. Minha opinião pessoal é que o meu avô conseguiu viver a vida toda com a minha vovó Maria por ela ter assumido desde sempre a função de babá e empregada doméstica. Mesmo como esposa ela mantinha a sua condição de mulher submissa, empregada. No entanto, a submissão da minha avó, não foi impedimento para que ela de certa forma e da sua maneira, desse as coordenadas nas decisões da casa. Meu avô, a meu ver, dependia e acabava fazendo tudo que ela queria, mas, achando que ele que estava mandando.

Esse argumento de que a mulher submissa consegue manipular e persuadir o marido é apresentando e criticado pela libanesa Joumana Haddad, no livro intitulado de "Eu matei Sherazade, confissões de uma árabe enfurecida". Haddad em seu livro já começa criticando a figura de mulher submissa e que ela não faz parte desse grupo. Para a autora, esse argumento de que a Sherazade representa essa mulher árabe ardilosa que consegue se safar é contraditória:

Eu nunca fui fã de Sherazade. Sei que, sendo uma mulher árabe e tudo isso, eu devia ter "admiração" por ela, ou ao menos apoiá-la. Mas não é o caso. Pode parecer, à primeira vista, que tenho ciúme dela. É Sherazade para lá, Sherazade pra cá: ela simplesmente pula de sua caixa de Pandora toda vez que uma escritora árabe é mencionada em alguma parte do mundo. Mas não tenho ciúme dela. Nem podia ter. Eu vou explicar o motivo. (Haddad 2011, 126)

No momento de escrita e pesquisa do texto de Tabule, ainda não conhecia este livro desta libanesa. Me deparei com o livro um mês antes da estreia. Mas, mesmo sem ter o lido anteriormente, Sherazade vai saltar da sua caixa de Pandora também no espetáculo Tabule e ela é, de certo modo uma referência para a personagem Zahara, por ser o primei- 
ro livro proibido que a personagem leu durante a adolescência. O pai de Zahara a expulsa de casa, entre outros motivos, pelo fato de encontrar a filha debaixo da cama lendo as Mil e uma noites, que segundo o pai da personagem, esse livro espalha a corrupção.

Segundo Haddad (2011) Sherazade é

Constantemente exaltada em nossa cultura por ser uma mulher instruída, engenhosa e de imaginação fértil, e inteligente a ponto de salvar a própria vida subornando "o homem" com suas histórias intermináveis. Mas eu nunca gostei desse lance de "subornar o homem". Em primeiro lugar, acredito que envia as mulheres a mensagem errada: "Persuada os homens, dê a eles as coisas que você tem e que eles querem, pois assim eles a pouparão". Corrija-me se eu estiver errada, mas parece óbvio que esse método coloca o homem numa posição de onipotência e a mulher, numa posição contemporanizadora, inferior. [...] Convença-as de que agradar o homem, seja com uma história, uma bela refeição, um par de seios de silicone, uma boa trepada ou o que for é a melhor maneira de "dar tudo certo na vida [...]. É isso que é considerado resistência? (128)

Apesar de estar de acordo com a escritora libanesa Joumana Haddad, acredito que "a pobre coitada teve de fazer o que era necessário" (128) e o exemplo de persuasão de Sherazade é uma das saídas que enfrentam muitas mulheres árabes. A minha vovó Maria era uma Sherazade? Submissa que tentava agradar o marido para ter o que ela queria? Sim, talvez. Conseguiu criar uma família de cinco crianças que não era dela? Sim, conseguiu. Criou os netos que a admiravam? Sim, conseguiu. Ela era feliz assim? Não sei. Mas também não demonstrou o contrário.

A personagem de Zahara tem muito da minha avó1 que nem libanesa era. Zahara, personagem de Tabule, tem a Sherazade como ídolo. As armas da Sherazade eram as que Zahara conseguiu manobrar. Ela não tem as armas e formação como a jornalista Joumana. Zahara é uma mulher comum expulsa de casa na adolescência, estuprada por um beduíno e que rodou por muitos países árabes até cair no Brasil. Sentiu na pele desde muito cedo o que era ser mulher em um mundo hostil e em uma cultura árabe. Tabule, meu unipessoal, nasce aí.

O leitor deve estar se perguntando, 1) qual a relação/importância entre essas informações que trago no início desse artigo com o desenrolar teórico-metodológico dessa pesquisa e os processos de encenação de Tabule, uma tragicomédia árabe? 2) Por que Tabule, uma comida árabe, para tratar de um tema tão polémico que é a questão da voz e visão de uma mulher do mundo árabe em terras brasileiras? 3) Por que a escolha do tema do 11 de setembro e da Primavera Árabe em uma peça de teatro a ser apresentada em Porto Velho, em plena Amazônia? 4) Porque um unipessoal para contar essa história? 5) Por que uma mulher para contar a história?

Essas perguntas são ponto de partida para o desenvolvimento e reflexão desta pesquisa e consequentemente, influenciaram na maneira em que essa reflexão teórica e relatos e vivencias de vida do ator vão diretamente e indiretamente influenciar e reverberar nas questões artísticas e pessoais envolvidas no processo de criação de um espetáculo unipessoal. ${ }^{2}$ 


\title{
TABULE ${ }^{3}$ E TABUS: IMAGINÁRIOS, ESTEREÓTIPOS E SUAS CONSEQUÊNCIAS - RINDO PARA NÃO CHORAR!
}

\author{
Atualmente, ser árabe é, em primeiríssimo \\ lugar —mesmo sem generalizar — dominar a \\ "arte da esquizofrenia!"
}

Joumana Haddad, 2011

Para Haddad (2011) o árabe hoje em dia precisa ser hipócrita: o (a) árabe não pode viver o que realmente quer viver, nem pensar de maneira honesta, espontânea e inocente. Ser árabe para ela significa "você está dividido, proibido de falar a verdade nua e crua (e a verdade é crua; esse é o seu papel e aí que está a sua força), porque a maioria árabe depende de uma teia de mentiras e ilusões reconfortantes" (2011, 17).

Ela afirma que nesta teia de mentiras

a vida e as histórias têm de ser abafadas, tolhidas e codificadas; reescritas para agradar os guardiões vestais da castidade árabe, para que estes possam ficar sossegados em relação ao fato de o delicado "hímen" árabe estar protegido do pecado, da vergonha, da desonra ou da mancha. (17)

O espetáculo teatral "Tabule, uma tragicomédia árabe" encenada a partir do texto dramático de mesmo nome, trata-se de peça que traz a cultura árabe como ponto de partida e de cruzamento entre o "pensamento" oriente versus ocidente. Enfatizo que quando digo que tem a cultura árabe como ponto de partida entre oriente e ocidente, já estou colocando em discussão a "ideia de pensamento".

Pensar um árabe romantizado em um camelo, ou uma odalisca de dança do ventre, kibes, esfirras, terrorismo e guerras, submissão da mulher, homens bombas, faz parte do imaginário do ocidente com relação aos árabes. Estamos diante de clichês e de verdades.

O ser humano árabe está sofrendo de esquizofrenia; uma esquizofrenia coletiva que todos nós vivemos, divididos entre o que nos disseram para acreditar e aquilo que realmente acreditamos, entre o que nos disseram para fazer e aquilo que realmente fazemos. (Bakkar, Jalila, apud Haddad, Joumana, 22)

Como fugir dos estereótipos que temos dos dois lados? Do oriente pensando o ocidente e vice-versa?

A personagem Zahara, acredita que a vida dela no Brasil seria melhor, pois aqui não teria violência contra a mulher e que ambos (homem e mulher) teriam os mesmos direitos e deveres. Ela, no Brasil, como mulher teria a mesma liberdade que o homem. Ou seja, os problemas estão no oriente, que para grande parte dos ocidentais é apresentando de forma estereotipada como atrasado, exótico, inflamado, temperamental (Said 2007).

Tabule, é uma salada libanesa. Dá nome a obra, fazendo referência à "mistura de ingredientes" que são colocados na salada tabule e que é digerida quase que diariamente na mesa libanesa. Essa salada de diferentes ingredientes na obra acaba sendo uma mistura de impasses: política, discriminação, extremismo religioso, misoginia, poligamia, homofobia, sexismo e arrogância do ocidente e que todos acabam digerindo. Por outro lado, apresenta também, 
o jogo com a palavra, tabule e tabu, pois considero que todos esses temas se apresentam como tabu e principalmente na voz de uma mulher árabe. Já no início da peça a personagem faz alusão ao tabule, como nome que ela dá para vagina no momento em que está no hospital para fazer uma cirurgia estética de recuperação da virgindade. Trocar o nome de órgãos sexuais por elementos da natureza são bastante comuns na poesia árabe.

No que tange aos temas e aos impasses presentes em Tabule, Haddad diz que:

Em terceiro lugar, ser árabe hoje em dia significa —e essa é a última declaração que tenho a fazer sobre esse assunto aqui- enfrentar uma série de impasses: o impasse do totalitarismo; o impasse da corrupção política; o impasse do favoritismo; o impasse do desemprego; o impasse do favoritismo; o impasse da pobreza, o impasse da discriminação de classe; o impasse do sexismo; o impasse do analfabetismo; o impasse dos regimes ditatoriais; o impasse do extremismo religioso; o impasse da fraude financeira; o impasse do desespero, do vazio e da falta de sentido; o impasse do conflito do Oriente Médio; o impasse da tragédia palestina; o impasse da parcialidade do Ocidente; o impasse da hostilidade, do medo, da arrogância, da desconfiança, do sentimento de superioridade do Ocidente... etc. $(2011,21)$

Zahara é uma libanesa das proximidades de Baalbeck que teve sua vida arruinada desde criança. Ela tinha uma família de cinco irmãs e um irmão, que era o favorito por ser o único homem. Ela sofreu na mão de um pai opressor e uma mãe submissa e teve a infância destruída quando foi estuprada por um beduíno. Ela descobre mais tarde que o beduíno teria feito um acordo com o seu pai que em troca de camelos, ofereceu a sua filha. Zahara, no momento da violência, tinha apenas 9 anos e o texto insinua que o abuso sexual ocorreu outras vezes. Este fato na peça de um abuso sexual aos nove anos não é absurda e acaba se justificando fora da ficção na declaração do aiatolá Khomeini, um famoso sacerdote islâmico:

O homem não deve ter relações sexuais com sua esposa antes de ela ter 9 anos de idade, seja de forma regular, seja de vez em quando, mas pode ter prazer sexual com ela, tocando seu corpo, abraçando-a ou esfregando-se nela, mesmo que ela seja apenas um bebê. Se ele a penetrar sem a deflorar, não tem nenhuma responsabilidade por ela. Mas, quando um homem penetra e deflora um bebê [...], então deve ser responsável por essa criança enquanto ela viver. (Haddad 2011, 37)

Saindo de uma infância traumática de violência sexual, já na adolescência Zahara lia e se encantava com as Mil e uma noites. Era o seu livro de cabeceira. Ou melhor, que ela tinha escondido debaixo da cama. Uma noite, seu pai a encontrou debaixo da cama lendo o livro. Ele, furioso, usou desse argumento e a expulsou de casa. Ele já não suportava a ideia de ter uma filha dentro de casa que havia sido violada.

Zahara, neste momento, começa a sua saga: vai ser dançarina e prostituta no Cairo onde ela afirma que se sentia verdadeiramente mulher, "nunca pensei que fosse me sentir tão mulher sendo puta" e se sente em uma posição privilegiada em que "recebo para humilhar os homens" e que "estava cansada de ser uma cera em que os homens moldavam de acordo com o prazer deles". Agora "quem manda é Zahara: amassa, pisa e bate". Entre suas andanças, ela atravessa o deserto e chega no Marrocos onde é obrigada a vender seu rim para uma clínica clandestina de tráfico de órgãos. A personagem precisa do dinheiro para sobreviver e voltar para o Líbano. De volta ao Líbano, Zahara tenta apagar o seu passado: faz uma cirurgia de recuperação do hímen e se casa com Salim, o dono de uma franquia de fast 
food árabe. Salim, abre uma filial no Brasil, o Habib's Brasil e Zahara vai com ele para Porto Velho, na Amazônia brasileira. A vida continua tranquila e seu passado só virá à tona no dia do velório de seu marido Salim, momento em que ela decide fazer do corpo de seu marido a sua pedra de lamentação e desabafar tudo para todas as pessoas que estão ali. Inclusive a verdade sobre a morte acidental de seu marido. Em um momento em que ela dormia, Salim, como era de costume, insistiu em transar com ela dormindo. Ela estava no meio de um pesadelo e deu um pontapé em seu marido que cai com a cabeça na quina da cama e morre. Zahara, no dia do velório traz todas essas verdades e assume que nunca se apaixonou por homem nenhum e que na verdade, odeia eles. Odeia beduíno, marroquino, libanês, egípcio, seu pai, seu irmão etc. E ao final depois de revelar tudo para a pedra da paciência, com a intensão de que a pedra exploda libertando-a de todo o seu tormento, Zahara decide ajudar a pedra a explodir: Ela anuncia que aquele velório é um atentado suicida, e já que todos acham que árabes são homens bomba, suicidas e que ninguém ali iria perdoa-la após ela ser sincera e contar toda a verdade. Ela decide eliminar todos. Mas, com uma diferença: ela não é suicida nem mulher bomba. Ela quer viver. Ela precisa ser livre. Para ela ser livre, eles precisam morrer, pois sabem demais. Zahara acende uma bomba dentro do caixão de Salim e sai correndo, anunciando ali um atentando. Sai correndo e fazendo referência que o público/convidados do velório morrem neste atentado.

O texto e a encenação de uma maneira irreverente e marcado por situações propositalmente exageradas e estereotipadas faz uma reflexão sobre o nosso olhar sobre a cultura do outro e vice-versa. Incialmente, o público desavisado pode pensar que se trata de uma comédia pastelão comercial que reforçará os estereótipos.

No entanto, já no início da montagem o público percebe que o texto é uma alfinetada onde se bate e assopra ou assopra e depois bate. Tabule traz como pano de fundo as Revoluções que ocorreram no mundo árabe e que a própria Zahara afirma que teve reuniões privadas com Bashar Al Assad, ditador sírio; Kadafi, ditador líbio, Mubarak, ditador egípcio, Zine el Abdine, da Tunísia e Ali Abdulah do lêmen.

\section{TABULEE SEUS INGREDIENTES - A MULHER NO COMANDO: DA COZINHA PARA AS RUAS}

O Boom das propagações do mundo árabe aparece após a queda das torres Gêmeas em Nova York no 11 de setembro. O acontecimento foi um fato marcante que mudou o pensamento mundial e pode-se considerar que, desde então, o mundo árabe veio à tona e várias eram as visões do ocorrido. Após os atentados do 11 de setembro, a busca pela cultura árabe se intensificou, até mesmo para saber se o que estava sendo publicado e divulgado pela mídia era realmente a verdade.

Segundo Milton Hatoum

contar a história do oriente não é fácil. Escrever sobre consciência histórica do oriente é complicado, pois, a história não terminou. A guerra continua. Os dois lados dos fatos produzem narrativas conflitivas. Para tratar da história do oriente, há sempre a versão de Israel, há a versão dos árabes e a versão "alucinada" dos norte-americanos. Quem contará a melhor história?

Tabule nasce em 2011 no momento em que dá início ao Arab Uprising, as revoluções no mundo árabe conhecida no Brasil como Primavera Árabe. 
O estereótipo dos árabes no Brasil sejam eles do Egito, Marrocos, Líbano, Arábia Saudita, etc, é de que todos são turcos. São todos iguais: "pão-duro", comerciantes, trapaceiros, e após o 11 setembro, são todos terroristas, homens bomba, muçulmanos, "filhos de Bin Laden". E no presente, com o assassinato de Osama Bin Laden, "os árabes" assim tratados, são chamados até de "órfãos do oriente". Agora já em 2017 são relacionados com os refugiados sírios e os conflitos do Estado Islâmico.

No Brasil, os árabes estão presentes em todas as regiões brasileiras. É possível conhecer e reconhecer a cultura árabe, embora muitas vezes considerada distante, pois esta fincou raízes no país. Na história da língua portuguesa é possível encontrar muitas palavras que vieram da língua árabe, e que chegaram ao Brasil devido à presença árabe nos países ibéricos. No que diz respeito à culinária brasileira é possível observar que os pratos mais tradicionais da cozinha árabe são completamente populares no Brasil: pão sírio, esfirra, quibe, tabule, entre outros. No dia 25 de março por exemplo é comemorado o Dia Nacional da Comunidade Árabe no Brasil.

E qual a corrente de pensamento que se formou no pós 11 de setembro e pós assassinato de Osama Bin Laden? Quais as consequências da Primavera Árabe para oriente e ocidente?

A partir da voz de uma mulher libanesa o texto trata de uma cultura patriarcal, machista, dominante e desigual e por meio de conflitos psicológicos e enfrentamentos culturais a peça permeia contextos históricos, políticos, econômicos e religiosos atravessados pelas questões de gênero e sexual.

"Não" existe igualdade sexual nem no ocidente nem no oriente. Mesmo onde a dominação sexual foi "superada" as práticas cotidianas continuam a reproduzir o preconceito e a desigualdade. A cultura patriarcal vem de longe e atravessa a cultura ocidental, africana, indígena, árabe e islâmica. Ser mulher, ser homem, ser heterossexual, ser homossexual, tem as suas implicações independentes da cultura a que se está inserido. Zahara, protagonista de Tabule, desde muito cedo reconhece todo o preconceito e desigualdade que existe em ser mulher e deseja ativamente que essa injustiça e desigualdade seja mudada.

Entre os estereótipos das mulheres nos países árabes e islâmicos, encontramos alguns relativos às mulheres: Elas são tidas como caladas, crédulas, cobertas com véus, submissas, integrantes de haréns imaginários e encerradas em papéis de gênero muito rígidos. Muitos desses estereótipos são baseados em situações pontuais, mas que não são regra, como por exemplo: apesar de ser proibido, ainda há tribos africanas que fazem uso da mutilação genital feminina; na Arábia Saudita até pouco tempo as mulheres não tinham certidão de nascimento; no Irã (país islâmico e não árabe) a vida das mulheres vale a metade da vida de um homem em um acidente e a mulher pode ser apedrejada em caso de adultério.

Atualmente podemos notar o contrário, pois foram muitos os levantes populares nos países árabes com a presença das mulheres: nos protestos do Egito e da Tunísia (Primavera árabe) em janeiro e fevereiro de 2011 foi possível detectar que muitas delas estavam na linha de frente nos protestos contra os governos ditadores. As mulheres contra a ditadura nas ruas manifestando e lutando pelos direitos dos árabes.

Segundo Haddad (2011) antes de tentar definir o que é uma mulher árabe, é necessário fazer uma pergunta:

Como uma mulher árabe típica é vista pelos que não são árabes? Não é uma visão formada basicamente na consciência coletiva do Ocidente por uma miríade de fórmulas e generalizações, nascidas de uma perspectiva orientalista persistente até agora, ou de uma visão hostil pós-11 de setembro, nascida do ressentimento, do medo ou de sentimentos de superioridade? (23) 
Zahara, inicialmente traz essa mulher pobre coitada, condenada de berço a obedecer ao pai, irmão, marido etc, uma mulher coberta por véus, vestido longo, vulnerável, indefesa. No entanto, Zahara aos poucos vai se mostrando ao público que o pensamento e ações dela não são diferentes das atitudes das mulheres do ocidente. Zahara aos poucos vai se despindo e se mostrando forte, já que precisou lutar muito e enfrentar essa sociedade que por si só queria silencia-la. Zahara mostra para as brasileiras que a mulher em geral acaba passando pelos mesmos problemas, mas com pinturas e camuflagens diferentes. Os clichês das mulheres árabes, que muito provavelmente povoam a cabeça do público que vai assistir Tabule vão aos poucos se colocando em cheque, em conflito. Os clichês existem, mas não é culpa somente do ocidente a sua construção. Haddad diz que

nós árabes somos igualmente culpados pela distorção de nossa imagem. Presos num círculo vicioso de defesa/ataque, fizemos e continuamos fazendo quase tudo o que podemos para incentivar a intolerância em relação a nós e para promover as imagens falsas e os clichês a respeito de nossas sociedades e culturas. Em resumo: temos talento quando se trata de sermos nosso pior inimigo. $(2011,25)$

Já no que diz respeito aos processos de montagem do espetáculo é importante destacar que o trabalho não foi escrito e ensaiado ao mesmo tempo. Incialmente foi feito o processo de pesquisa e escrita do texto dramático e posteriormente deu-se os ensaios para a construção cênica. De posse do texto escrito por mim, ia para a sala de ensaio com músicas árabes de fundo e começava a ensaiar e a desenhar cenas. Filmava trechos, convidava um amigo ou diretor para assistir alguns ensaios, fazia improvisações livres a partir do texto, etc.

A medida que ensaiava, ia definindo figurino pensando na movimentação de cena, trocas de figurinos e tempo de uma cena a outra; já pela movimentação que criava nas improvisações, comecei a definir cenário.

Posteriormente convidei um dançarino de dança do ventre para fazer um trabalho de preparação corporal comigo e em um ensaio após uma improvisação que ele participou comigo, decidi convidá-lo para pontuar uma cena do espetáculo com uma coreografia. O bailarino aceitou e começamos a trabalhar juntos em Tabule. O dançarino Thallysson Lopes participou da cena das mil e umas noites com uma coreografia de dança do ventre e trouxe uma grande quebra na cena pois todos esperam uma dançarina e quem entra na cena é um dançarino. Assim, com a participação do dançarino Thallysson eu pude contar com um olhar externo na construção das cenas pois ele abraçou o trabalho como um todo e não somente na construção de uma coreografia.

Assim a montagem foi se construindo e se costurando a partir do texto e das improvisações nos ensaios a partir das danças, músicas, cenário, figurinos e adereços que foram compondo o desenho cênico e de certo modo dirigindo os rumos nas escolhas e ordem de cenas. 


\section{CONSIDERAÇÕES FINAIS}

Tabule, é um unipessoal em que eu me coloco como ator-autor (Betancourt 2015), neto de libanês que escreveu, dirigiu e atuou. Foi escolhido o unipessoal por naquele momento da pesquisa eu ter me visto sozinho diante desse tema. Um ator em solidão (Betancourt 2015) que buscava um discurso próprio construído a partir dos materiais, experiências, inquietações do seu próprio imaginário. Marcado pela necessidade de dar voz as minhas próprias inquietações (Betancourt 2015).

Assim, em plena região norte do Brasil, entre bois-bumbás, ribeirinhos, indígenas, garimpeiros, construção de hidrelétricas e os constantes problemas no campo ambiental, decidi por colocar em cena uma mulher árabe e seus conflitos.

Em meados de 2010 e 2011 estava começando os levantes no mundo árabe. A Síria ainda não tinha iniciado a guerra tão catastrófica que se mantém até hoje, ainda não tinha dado início aos fluxos migratórios e não se ouvia falar em refugiados sírios. Os desmembramentos dessas revoluções só vieram à tona depois da estreia da peça.

Na estreia de Tabule, já havia ocorrido os levantes na Tunísia, no Egito, na Líbia, no lêmen e pensar em Tabule na Amazônia ainda estava distante para muitos. Na região norte é muito comum que os grupos sejam praticamente obrigados a montar trabalhos em que estejam claramente estampados o tom regional. Tabule, assim, iria contra a maré por não ser considerado "um tema amazônico".

Era um projeto muito particular, assim me diziam os críticos. O trabalho foi inclusive indicado para circulação no Amazônia das Artes, pelo Sesc (RO) mas, negado com o argumento que não teria relação com a região Amazônia. Trago esse exemplo para exemplificar o quão distante muitas vezes achamos que estamos com relação ao problema que mora ao lado. Hoje, vejo que Tabule foi um dos primeiros levantes, no campo do teatro, em que anunciava/ acompanhava as grandes revoluções no mundo árabe e as questões relacionados as liberdades, xenofobias, guerras, imigrações etc. Ou seja, a nossa crise contemporânea que se mantem ainda hoje e não temos ideia de onde isso vai dar: Coreia do Norte, Rússia, Estados Unidos, China, Síria e quem mais vier para a cena.

Um ator em cena, dando voz às mulheres e histórias que permearam a infância, adolescência e vida adulta. Tive sempre a preocupação em não trazer o mundo árabe como fetiche, romântico, atrasado. Para isso, as pesquisas, os relatos, os depoimentos foram importantes. Essa pesquisa apesar de ter sido iniciada no final de 2010 ainda reverbera hoje. Não está encerrada.

Hoje trabalho a questão do Teatro e Política no Oriente Médio: paralelos com a América Latina e no ano passado visitei o Líbano para buscar subsídios para iniciar esta outra fase de experimentação cênica. Mas, o principal de tudo isso: a arte, especificamente o teatro, me acompanha de uma forma sensível me atravessando pelo que está latente no momento histórico em que vivo e me inquieta, o que questiona. Deixei fluir o que me pulsava, o que me movia e me angustiava naquele momento. Li, reli, pesquisei, experimentei cenicamente. Me recolhi em solidão. Fui sincero com o tema tratado e sensível para tentar perceber e dar voz a algo que eu sentia necessidade de dizer em cena. Que fazia sentido para mim naquele momento. Hoje, faço uma reflexão e vejo que estava acompanhando um fluxo migratório natural pessoal e profissional, que não era só do oriente. Não era só do lado de lá. Mas, aqui também no Brasil, na região norte, em Porto Velho, Rondônia, Amazônia. 


\section{NOTAS}

${ }^{1}$ Minha avó que trato aqui não é a biológica. Não conheci a avó biológica. Minha mãe também não. Tivemos notícias da família biológica da minha mãe quando eu já era adulto e justamente alguns anos após a sua morte.

2 Em 2012 conheci em Salvador (BA), na Universidade Federal da Bahia, o ator e professor Juan González Betancour, que estudou comigo no doutorado. A sua pesquisa se chamou 0 ator em solidão, e ele tratava da questão do autor-ator e a criação de unipessoal. A partir das conversas com ele e da aproximação de seu pesquisa, pude rever conceitos e ampliar o universo do meu trabalho.

${ }^{3}$ Tabule teve estreia no SESC-RO em novembro de 2011 se apresentou em várias locais: em 2012 Salvador (BA) ficou em cartaz na programação do Gayboa do Teatro Gamboa nova, no mês de setembro programação da diversidade. Em 2013 no presidio feminino de Porto Velho, na programação do Palco Giratório; Em Cacoal (RO) em 2013; em 2014 no Festival de Teatro Rosa de Bogotá, Colômbia; Ainda em 2014 na Universidade Federal de Santa Maria (RS); em 2015 na Funarte, em São Paulo (SP) e em Vilhena (RO); em 2016 no Teatro Estadual de Porto Velho no dia das Mulheres.

\section{REFERÊNCIAS}

Arbex, José Júnior. 2002. Terror e Esperança na Palestina. São Paula: Casa Amarela.

Cojean, Annick. 2012. O Harém de Kadafi: a real história de uma das jovens presas do ditador da Líbia. $2^{a}$ ed. Tradução Saulo Krieger. Campinas, SP: Verus Editora.

González Betancur, Juan David. 2015. “O ator em solidão: passagem de intérprete a autor da cena na criação de um espetáculo unipessoal." http://wWW.repositorio.ufba.br:8080/ri/handle/ri/17714

Haddad, Joumana. 2011. Eu matei Sherazade: confissões de uma árabe furiosa. Tradução de Dinah de Abreu Azevedo. Rio de Janeiro: Record.

Hatoum, Milton. 2008. Relato de um certo oriente. São Paulo: Companhia das Letras.

Jabal, Ayesha. Combatentes de Allah: a jihad no sul da Ásia. Tradução Luiz Roberto Mendes Gonçalves. São Paulo: Larousse do Brasil, 2009.

Khalidi, Ismail; Wallace, Naomi, orgs. 2015. Inside/outside six plays from Palestine and the diaspora. Introduccion by Nathalie Handal. Theatre Communications Group, Inc., New York, NY.

Rahimi, Atiq. 2009. Syngué Sabour. Pedra-de-paciência. Tradução Flávia Nascimento. São Paulo: Estação Liberdade.

Said, Edward. 2007. O oriente como invenção do ocidente. São Paulo, Companhia das Letras.

Sasson, Jean P. 2010. Princesa: a história real da vida das mulheres árabes por trás de seus negros véus. $40^{a}$ ed. Tradução: Regina Amarante. Rio de Janeiro: BestSeller.

Sasson, Jean P. 2010. Princesa Sultana: sua vida, sua luta. $5^{a}$ ed. Tradução Therezinha Monteiro Deutsch, Sylvio Deutsch. Rio de Janeiro: BestSeller.

Sasson, Jean P. 2010. Mayada, filha do Iraque: a história de uma mulher que sobreviveu ao regime de Saddam Husseim. $6^{a}$ ed. Tradução Marcelo Almada. Rio de Janeiro BestSeller.

Sonn, Tamara. 2011. Uma breve história do Islã. Tradução de Maria Helena Ribinato Rodrigues de Sousa. Rio de Janeiro: José Olympio.

Telhami, Shibley. 2013. The world through Arab eyes: Arab public opinion and the reshaping of the Middle East. New York: Basic Books. 


\section{Cómo citar este artículo:}

Lopes Júnior, José Maria. 2017. “Tabule e tabu: no palco uma salada de gênero, sexualidade, política e revolução a partir do cómico, se não fosse trágico." Cuadernos de Música, Artes Visuales y Artes Escénicas 12 (2): 103-115. https://doi. org/10.11144/javeriana.mavae13-1.ttnp 